\title{
A model to support the public administration decisions for the investments selection on historic buildings ${ }^{\text {t3 }}$
}

\author{
Antonio Nesticò $^{\mathrm{a}, *}$, Pierluigi Morano $^{\mathrm{b}}$, Francesco Sica ${ }^{\mathrm{c}}$ \\ a Department of Civil Engineering, University of Salerno, Fisciano, Italy \\ ${ }^{\mathrm{b}}$ Department of Science of Civil Engineering and Architecture, Polytechnic University of Bari, Italy \\ c Department of Architecture and Design, University "La Sapienza", Rome, Italy
}

\section{A R T I C L E I N F O}

\section{Article history:}

Received 19 November 2017

Accepted 13 March 2018

Available online $\mathrm{xxx}$

\section{Keywords:}

Historic buildings

Economic evaluation

Sustainable development

Multi-criteria decision analysis

Discrete linear programming

\begin{abstract}
A B S T R A C T
The historical buildings can become an instrument for the growth of a territory in connection with the historic and artistic value, the ability to characterize environments and urban, rural and natural landscapes and on the basis of historical and documentary interest. This is confirmed in the numerous legislative measures that deal with urban planning at the international level. Most of the time, however, the interventions on the historical-architectural building heritage do not respond to logic capable of simultaneously ensuring the conservation and valorization. This problem is accentuated when the decision-making process is not supported by operating logical models capable of bringing into account the many effects of an investment, which are not only financial, but also social, cultural and environmental nature. The operational research, in particular discrete linear programming crossed with multicriteria analysis, can support the definition of useful models to the selection of investments on historical buildings. Intended for public authorities called to choose the projects to be financed, the model defined and tested in the present work can be easily adapted also to the case of resources allocation by private investor. The application of the model to a concrete case, concerning the definition of the projects portfolio for the valorization of buildings of historical-architectural value in a Municipality of South Italy, confirms the potential of the instrument in analysis.
\end{abstract}

(c) 2018 Elsevier Masson SAS. All rights reserved.

\section{Introduction}

Like the principal European countries, Italy is experiencing a difficult economic-financial phase, sharpened from the strong incidence of public debt and the consequent dimension of interests to be repaid. In this scenery, in which do not remain margins for further tax levies, the only way to combat the crisis is to support the rigour and efficiency of spending through the development of strategies for the effective use of available resources.

Among the policies to which compete the greatest potential, stand out those that point to the development of the Public entities assets, in particular those on disuse or underutilized historical buildings. They are "buildings that are significant in the history of architecture, that incorporate significant architectural features,

\footnotetext{
The contribution to this paper is the result of the joint work of the three authors, to which the paper has to be attributed in equal parts.

* Corresponding author.

E-mail addresses: anestico@unisa.it (A. Nesticò), pierluigi.morano@poliba.it (P. Morano), francescosica2690@gmail.com (F. Sica).
}

or that played significant historic roles in local cultural or social development; may or may not be officially designated" [1-3]. The redevelopment of these goods can act as a flywheel for the revival of entire urban areas, specially in the contexts characterized by an intense deterioration in which the cultural good represents often the only regard element of leverage [4]. The logic is to "produce" the good of cultural value in the respect of its properties, in order to generate benefits for all community [5-7]. In fact, historic buildings often located in the city centre of interesting areas from the environmental point of view constitute a catalyst for urban regeneration, due to their symbolic value for the entire community [8]. The European Framework Program for Research and Innovation (Horizon 2020) points out the positive effects that may result from the valorization of the public buildings of cultural heritage, as a synthesis of the traditional passive protection of these assets-that is proved unfit as well as financially unsustainable for the Public Administration-and their productive use, through modalities compatible with their nature and vocation [9-11].

In this context, a leading role is provided by the decision support tools for the selection of initiatives to be implemented [12-14], especially in the case of complex interventions, characterized by 
budgetary constraints, numerous variables in play, and the presence of stakeholders expressing conflicting interests and purposes [15-18].

In these circumstances it is necessary to employ a viable systems approach (VSA), that is an approach updated by considering implications of the highly dynamic environment that characterizes business contexts and in which complexity plays a central role [19]. This is an approach increasingly used in the field of investments on cultural goods, able to return an integrated reading of the property value as a function of the belonging context [20,21]. The VSA approach implements multidimensional models to rationalize the choices operated by multiple criteria that take into account simultaneously of financial, social, cultural and environmental aspects $[22,23]$. It is therefore to find the compromise solution which simultaneously maximizes the decisor objectives respecting the system constraints.

\section{Research aims}

With reference to the framework outlined in the present work it is defined and experienced a support model to public administration decisions involved in the definition of investment program on historical buildings in the case of budgetary constraints.

Starting from the set of projects presented to the financing, the model should allow:

- to isolate the initiatives "portfolio", capable of achieving better the programme objectives in the respect of the available resources and other constraints;

- to produce a reporting framework on which decision-makers can carry out rational and conscious assessments;

- to improve the coherence and transparency of the choices, with the translation of the constraints and programme objectives in mathematic relations of immediate understanding;

- to modify easily relationships that constitute the model constraints, so as to adapt them to technical, political and economic context each time considered.

Developed by crossing the linear programming algorithms with the multi criteria decision analysis (MCDA), the model is built using the A Mathematical Programming Language (AMPL) software. It is about a simple and intuitive tool used for structuring the mathematical programming problems. Then the resolution happens with the use of specific solver (CPLEX, FortMP, KNITRO, etc.).

This paper is structured as follows. In Section 3, notes on the applicability of linear programming and multicriteria evaluation to the valorization issues of cultural value goods are reported. In Section 4 there is outlined the model, of which the limits and potentialities are illustrated. In Section 5 the model is specified and applied to a real case, relative to the choice of a set projects for the historical-architectural buildings valorization to be carried out in a Municipality of South Italy, and the results are illustrated. In Section 6 the work conclusions are discussed.

\section{Multi-criteria decision analysis and linear programming for the investment projects selection on historical buildings}

The limits of the "pure" conservation of the historical-architectural building heritage-oriented policies become more evident when the evaluation of the interventions is conducted both by reason of the extra-monetary effects generated, and on the basis of the canonical performance indicators $[24,25]$. In fact, the MCDA provide an ample vision and systematic of the project effects, on the basis of quantitative and qualitative characteristic of the building to recover $[26,27]$. These are extrinsic and intrinsic factors that require the identification of criteria for evaluating the value of use and the proper value of the historical building. While the first one, said also instrumental value, refers to the cash flows that the building is able to produce on the time, the second, named intrinsic value or value independent from the use, expresses the whole of the relations that tie the good to the belonging context. The intrinsic properties relate to: (a) the environmental quality, (b) the historical quality, (c) the architectural quality, (d) the quality of any historical-artistic intakes inside, and (e) the age. Instead the environment-building relations relate: (f) the current usability, (g) the potential usability, and (h) the accessibility [28].

In reason of the historical building nature and its uniqueness and not reproducibility, the resort to the MCDA techniques lets take into account then in the evaluation of multiple aspects useful to protect the integrity of the good and to satisfy the needs with the community [29,30].

Operationally, the MCDA faces the projects selection problems through two steps:

1. preliminary analysis, aimed at identifying the alternatives and their socio-cultural and environmental components affected by the intervention.

2. economic evaluation of projects, according to the impact generated on the various components.

It is evident that the choice process needs rational, transparent models easy to use, aimed at identifying the best solution in respect of legal, technical, administrative, social and/or economical constraints that connote the system.

A valid support to this purpose is given by operational research algorithms, that allow to solve problems about the optimal use of scarce resources in complex contexts characterized by numerous constraints and many variables [31]. In fact, many cases of selection can be effectively solved with optimization algorithms writing mathematical programming functions of the type:

$\left\{\begin{array}{l}C\left(x_{1}, \ldots, x_{n}\right) \\ \varphi_{m}\left(x_{1}, \ldots, x_{n}\right) \leq b_{m} \\ x \in X\end{array}\right.$

where $x_{i}$ is the $i$ th variable of the problem; $C(x)$ is the objective function; $\left(\varphi_{m}\right)$ represents the set of constraints, with the vector of known terms $b_{m}$ which provides the limits to be respected in the definition of the optimal value [32,33].

The analysis scheme must formalize the decision-making problem using a mathematical language capable of simulating the behaviour of the economic system investigated [34].

Frequently, both the objective function and the set of the constraints are expressed through linear relations, which return therefore a linear programming model. Although the assumption of linearity may seem restrictive in relation to the complexity of the real phenomenon, it generally does not cause excessive approximations and finds ample feedback in practice, as it is evident in the context of the selection between interventions for the recovery and valorization of the historical-architectural heritage [35,36].

The applications of linear programming are in many disparate sectors. In particular, they are:

- in corporate finance and project management [37-44];

- in land-use planning [45,46], as well as implementing geographic information systems [47-49] and with the elaboration of decision maps able to consider territorial components of different nature [50,51];

- in urban planning and economic projects evaluation [52-56]. 


\section{The model}

With the aim of pursuing many $m$ objectives about the rehabilitation and valorization of the historical-architectural heritage, a selection problem among $n$ projects not all realizable for constraints of budget is considered.

Such a problem can be modelled and solved through mathematical programming, in particular the linear one, where both the objective function that the constraining relations can be write in simple polynomial form. With the condition that the individual project constitutes a unitary initiative, and therefore cannot be divided, in the present work we use discrete linear programming (DLP) and in particular the Branch \& Bound algorithm, which operates by partitioning and ramifying (branch) the set of solutions, up to find the result that respects the limit value (bound) fixed for the return function [57-60].

In fact, the choice of the projects portfolio that, under the constraints of different nature must compose an investment program, shows marked similarities with the operational research paradigm known as "knapsack problem", that consists in filling a knapsack of $W$ capacity with $n$ objects, each of which has $w_{i}$ volume and $v_{i}$ value, so as to make maximum the value of its content. The correspondences between the knapsack elements and the elements of the investment program are:

- the $W$ knapsack capacity is reflected in the eligibility domain of the design solutions circumscribed by the constraints that determine the acceptability of the projects;

- the $n$ objects to fill the knapsack correspond to the projects presented to the financing and to be subjected to selection;

- the $v_{i}$ value of the $i$ th object is the generic project capacity to pursue the programme objectives measured in the terms of the evaluation criteria adopted;

- the $w_{i}$ volume of the $i$ th object is equal to the investment project cost that corresponds to or, more in general, the set of conditions that define the feasibility in function of the existing constraints;

- the maximization of the knapsack contents value has its parallel in the investment programme objectives.

In the present case the model in question can be schematized as in Table 1 with AMPL's own syntax.

The $n$ investment projects about important historical building (set PROJECTS) are valued according to $m$ indicators (set INDICATORS).

In section PARAMETERS there are numeric values that define the problem to be resolved, namely:

- the budget available (param BUDGET),

- the vector of the investment costs for each project (param cost $\{$ PROJECTS $\}$ ),

- the $m$ vectors of indicators (param INDICATORj \{PROJECTS $\}$ ),

- the vector of the $p_{j}$ coefficients representative of the weights assigned by the decision maker to each criterion (param $p_{j}$ ).

After having defined the unknown of the problem (var $x\{i$ in PROJECTS $\}$ in $\{0,1\}$ ), the writing of the objective function, in which there are the coefficients $p_{j}$ of the weights attributed by the decision-maker to the $j$ th criterions, is:

MAXIMIZE (or MINIMIZE) objective $: \operatorname{sum}\{i$ in PROJECTS $\}$

$\left\{p_{1} \times \operatorname{INDICATOR}_{1}[i]+p_{2} \times \operatorname{INDICATOR}_{2}[i]+\cdots\right.$

$\left.+p_{j} \times \operatorname{INDICATOR}_{j}[i]+\cdots+p_{m} \times \operatorname{INDICATOR}_{m}[i]\right\} * x[i]$
Table 1

The model for decision analysis.

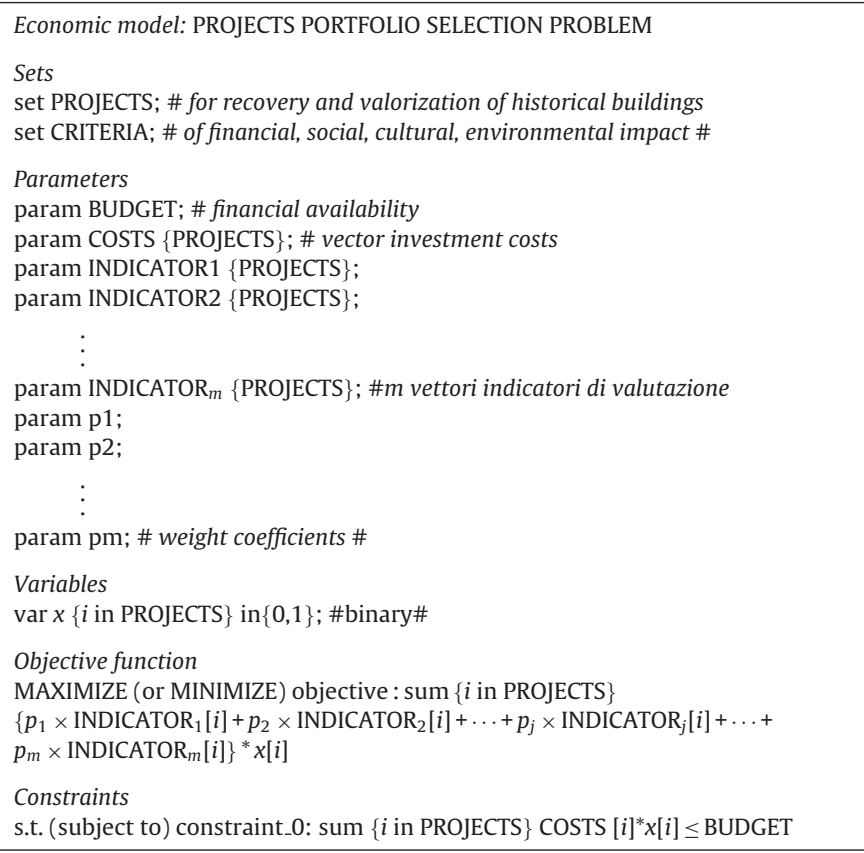

where all indicators are of the same importance, the objective function assumes the simplest formulation:

MAXIMIZE(or MINIMIZE)objective $: \operatorname{sum}\{i$ in PROJECTS, $j$

in INDICATORS $\}$ INDICATORS_unit $[i, j] \times x[i]$.

This is a linear expression that maximizes the capacity of investments to pursue the different objectives related to the recovery and valorization of the existing. The optimal value returned by this function depends on the problem constraints, as described in the COSTRAINTS section. In Table 1 , the only constraint concerns the available financial allocation:

s.t. vinc_0 $: \operatorname{sum}\{i$ in PROJECTS $\}$ COSTS $[i] \times x[i] \leq$ BUDGET

The .mod file is written in parametric form through AMPL without specifying the data used. Instead they are written in a specific .dat file.

\section{Case study}

The case study concerns a real situation regarding the selection of a projects portfolio to be financed from a set of 20 projects under validation aimed at the recovery of buildings with historical-architectural value, predominantly building structures belonging to religious complexes or of noble palaces. The field of interest coincides with a vast area adjacent to the Campus of the University of Salerno (Italy) and included in the Fisciano Municipality. Fig. 1 allows to geo-referenced the objects subject to intervention marked with red colour.

In view of the limited budget available, it is intended to finance the projects subset able to generate the best relapses on the territory in financial, social, cultural and environmental terms.

Two issues about this problem should be remarked. Primarily, it might happen that downstream of the selection the funds allocated to the program are not completely used: if the sum of the projects costs included in the "financial ceiling" is not equal to the amount of the program resources a residue not sufficient to cover other projects remains. The consequence is that the uncommitted sums 


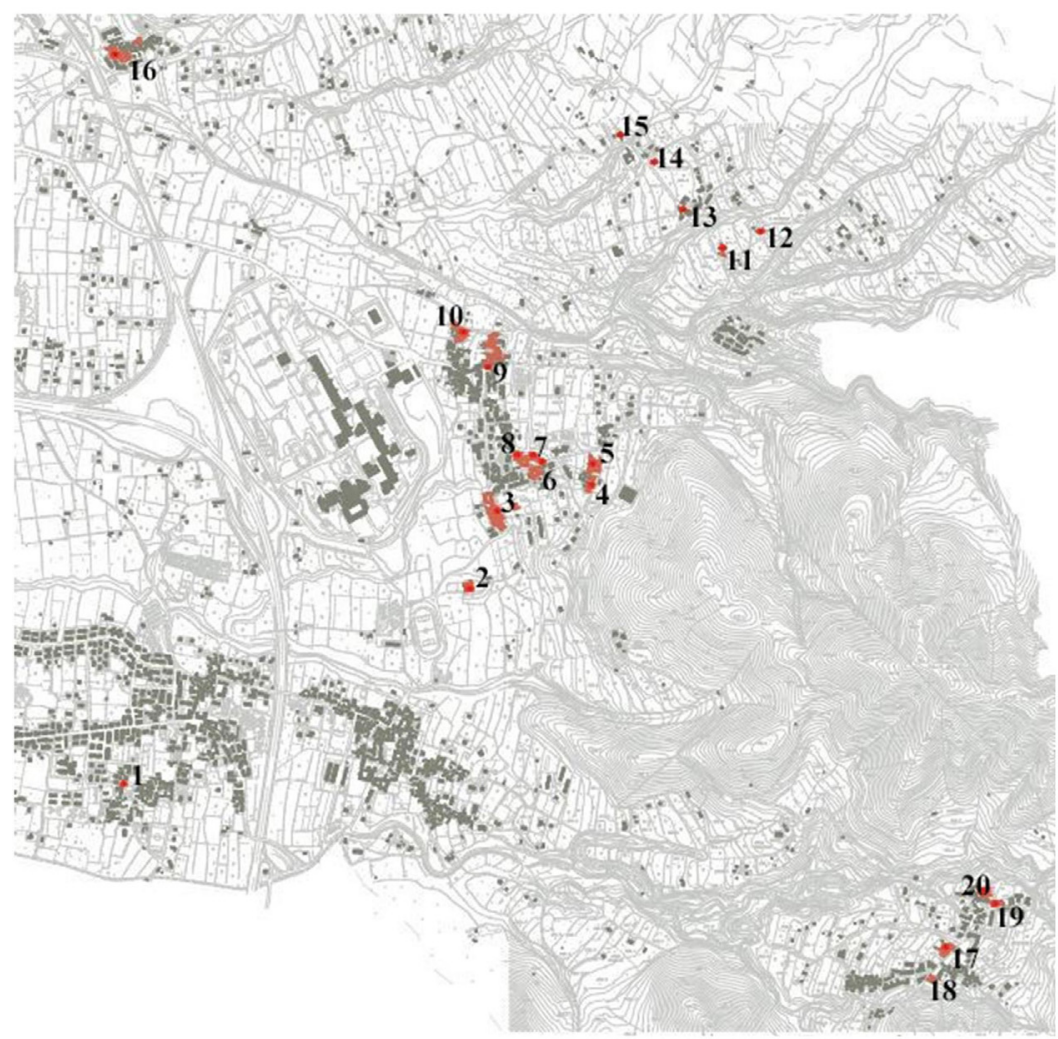
1. ST. QUIRICO'S CHURCH
2. ANNUNZIATA CHURCH
3. ST. JOHN'S CHURCH
4. COVEN-PALACE BLESSED IMMACULATE
5. "MADONNA OF CARMEL" CHURCH
6. GALDIERI PALACE
7. ST. MICHELE MIDDLE SANCTUARY
8. ST. NICHOLAS'S CHURCH
9. MAIORINO PALACE
10. ST. JOSEPH'S MONASTERY
11. EX CHAPEL OF NEGRI FAMILY
12. CHURCH ST. PETER THE APOSTLE
13. COVEN OF BLESSED ROSARY
14. FIOCCHI PALACE
15. ST. SPIRIT'S CHURCH
16. DE FALCO PALACE
17. "MADONNA OF HAY" CHURCH
18. COVEN TO GAIANO
19. ST. SOSSIO'S CHURCH
20. SEVENTEENTH-CENTURY BUILDING

Fig. 1. Excerpt from the municipal mapping and identifying properties.

return to the investor, thereby losing investment and development opportunities for the territorial area to which they were destined.

Secondly, it is not said that proceeding-in a canonical way-by financing projects until the depletion of available resources, in accordance with the priority order defined with the chosen indicator (e.g. NPV, IRR, etc.), determines the maximization of the decision maker objectives. Combinations of projects other than the one identified by the priority list, while respecting the budget constraint, could achieve the objectives of the programme to a greater extent.

For this reason, the objective pursued with the model in question is the individualization of the projects combination, also different from the sequence individualized by the list of priority, which respecting the constraint of the budget allows to reach at most the programmatic objectives.

Returning to the case study, each historical building is assessed on the basis of the following qualitative and quantitative criteria:

(a) architectural quality;

(b) compatibility of utilization expected for the projects with the historical-architectural features of good;

(c) financial relapses caused by investment;

(d) occupational effects;

(e) cultural impact on community;

(f) environmental sustainability of the intervention in view of the technologies and the systems expected for energetic saving.

The corresponding performance indicators are:

(a) judgement on architectural and historical-cultural valences of the building (QUALITY). Relating to opinions provided by experts, the assessment is explained through values scale from 1 to 5 growing to the components that have value;

(b) features of the project in relation to the conservation of the existent historical material (ACTION). The numerical values, expressed in cubic metres of volumetry, are positive (therefore the choice of these is preferred) in case of increase of cubic capacity at present not available, although keeping intact the historical texture of good; while they are negative (thus penalizing the choice) when the intervention causes destruction of the historicized material;

(c) Internal Rate of Return (IRR), as deduced from the economic investment evaluation;

(d) number of new permanent workers ( $\mathrm{N}^{\circ}$ OF PERMANENT WORKERS) that the initiative is able to produce;

(e) indicator (comunity) which expresses, through increasing scores 1, 3, 5, 7 and 9, increasing the capacity of the project to generate benefits to the community in terms of added services;

(f) the level of use of technologies and systems for energy saving (IMPA), expressed through a 1-9 points scale where the value 1 indicates a very bad performance and the value 9 a very good. So, the project initiatives that offer useful solutions to reduce the release of carbon dioxide into the atmosphere are favoured.

For the 20 investment projects analyzed, the parameter values are in Table 2.

The values obtained for the ACTION, IRR, $\mathrm{N}^{\circ}$ OF PERMANENT WORKERS, COM and IMPA parameters refer to the unit investment cost. At this point, the values obtained for all six indicators are to be back to a common evaluation scale, so that they can be compared. In the case in question, normalization is conducted by dividing each attribute by the corresponding maximum value.

It comes to the normalized matrix of Table 3, which also includes a synthesis indicator that expresses the Value of the Good (VALUE) through the sum of the normalized attributes of the $i$ th project evaluated according to all the $j$ th criteria. The analysis is conducted assuming that all evaluation criteria are of the same importance. 
Table 2

Matrix of multicriteria analysis.

\begin{tabular}{|c|c|c|c|c|c|c|c|c|}
\hline No. & Projects & $\begin{array}{l}\text { Cost (in } \\
\text { thousand of } € \text { ) }\end{array}$ & $\begin{array}{l}\text { Quality (1-5 } \\
\text { scale) }\end{array}$ & Action $\left(\mathrm{m}^{3}\right)$ & $\operatorname{IRR}(\%)$ & $\begin{array}{l}\text { No. of } \\
\text { permanent } \\
\text { workers }\end{array}$ & $\begin{array}{l}\text { COM. (1-9 } \\
\text { scale) }\end{array}$ & $\begin{array}{l}\text { IMPA (1-9 } \\
\text { scale) }\end{array}$ \\
\hline 1 & ST. QUIRICO'S CHURCH & 1500 & 2 & 0 & 4.50 & 0 & 7 & 3 \\
\hline 2 & ANNUNZIATA CHURCH & 1750 & 3 & 0 & 5.30 & 3 & 5 & 1 \\
\hline 3 & ST. JOHN'S CHURCH & 500 & 5 & 150 & 6.12 & 0 & 9 & 5 \\
\hline 4 & CONVEN-PALACE BLESSED IMMACULATE & 2100 & 3 & 100 & 9.20 & 8 & 1 & 7 \\
\hline 5 & “MADONNA OF CARMEL” CHURCH & 1000 & 2 & 0 & 7.10 & 5 & 3 & 3 \\
\hline 6 & GALDIERI PALACE & 3100 & 4 & 0 & 10.12 & 9 & 9 & 1 \\
\hline 7 & ST. MICHELE MIDDLE SANCTUARY & 2400 & 5 & -50 & 9.80 & 7 & 1 & 5 \\
\hline 8 & ST. NICHOLAS'S CHURCH & 1110 & 2 & 10 & 6.10 & 0 & 1 & 3 \\
\hline 9 & MAIORINO PALACE & 2810 & 2 & 0 & 8.20 & 10 & 9 & 3 \\
\hline 10 & ST. JOSEPH'S MONASTERY & 1480 & 4 & 60 & 10.10 & 8 & 9 & 7 \\
\hline 11 & EX CHAPEL OF NEGRI FAMILY & 300 & 3 & 0 & 4.30 & 0 & 1 & 1 \\
\hline 12 & CHURCH ST. PETER THE APOSTLE & 650 & 2 & 0 & 6.05 & 2 & 1 & 1 \\
\hline 13 & CONVEN OF BLESSED ROSARY & 4100 & 4 & 60 & 8.19 & 8 & 7 & 5 \\
\hline 14 & FIOCCHI PALACE & 3850 & 3 & 0 & 11.00 & 6 & 9 & 1 \\
\hline 15 & ST. SPIRIT'S CHURCH & 2180 & 4 & -100 & 5.01 & 0 & 7 & 9 \\
\hline 16 & DE FALCO PALACE & 1800 & 5 & 30 & 12.00 & 7 & 7 & 5 \\
\hline 17 & "MADONNA OF HAY" CHURCH & 2000 & 5 & -750 & 10.00 & 9 & 9 & 9 \\
\hline 18 & CONVEN TO GAIANO & 1950 & 2 & 0 & 9.00 & 0 & 9 & 1 \\
\hline 19 & ST. SOSSIO'S CHURCH & 900 & 4 & 15 & 7.15 & 3 & 5 & 5 \\
\hline 20 & SEVENTEENTH-CENTURY BUILDING & 1170 & 2 & -50 & 6.18 & 0 & 5 & 5 \\
\hline
\end{tabular}

Table 3

Normalized multicriteria matrix.

\begin{tabular}{|c|c|c|c|c|c|c|c|c|c|}
\hline No. & Projects & Cost & Quality & Action & IRR & No. of permanent workers & COM. & IMPA & Value \\
\hline 1 & ST. QUIRICO'S CHURCH & 1500 & 0.400 & 0.000 & 0.209 & 0.000 & 0.259 & 0.200 & 1.069 \\
\hline 2 & ANNUNZIATA CHURCH & 1750 & 0.600 & 0.000 & 0.211 & 0.317 & 0.159 & 0.057 & 1.344 \\
\hline 3 & ST. JOHN'S CHURCH & 500 & 1.000 & 1.000 & 0.854 & 0.000 & 1.000 & 1.000 & 4.854 \\
\hline 4 & CONVEN-PALACE BLESSED IMMACULATE & 2100 & 0.600 & 0.159 & 0.306 & 0.705 & 0.026 & 0.333 & 2.129 \\
\hline 5 & "MADONNA OF CARMEL" CHURCH & 1000 & 0.400 & 0.000 & 0.495 & 0.925 & 0.167 & 0.300 & 2.287 \\
\hline 6 & GALDIERI PALACE & 3100 & 0.800 & 0.000 & 0.228 & 0.537 & 0.161 & 0.032 & 1.758 \\
\hline 7 & ST. MICHELE MIDDLE SANCTUARY & 2400 & 1.000 & -0.069 & 0.285 & 0.540 & 0.023 & 0.208 & 1.987 \\
\hline 8 & ST. NICHOLAS'S CHURCH & 1110 & 0.400 & 0.030 & 0.387 & 0.000 & 0.051 & 0.273 & 1.140 \\
\hline 9 & MAIORINO PALACE & 2810 & 0.400 & 0.000 & 0.204 & 0.658 & 0.178 & 0.107 & 1.547 \\
\hline 10 & ST. JOSEPH'S MONASTERY & 1480 & 0.800 & 0.135 & 0.476 & 1.000 & 0.338 & 0.473 & 3.222 \\
\hline 11 & EX CHAPEL OF NEGRI FAMILY & 300 & 0.600 & 0.000 & 1.000 & 0.000 & 0.185 & 0.333 & 2.119 \\
\hline 12 & CHURCH ST. PETER THE APOSTLE & 650 & 0.400 & 0.256 & 0.649 & 0.569 & 0.085 & 0.154 & 2.114 \\
\hline 13 & CONVEN OF BLESSED ROSARY & 4100 & 0.800 & 0.049 & 0.139 & 0.361 & 0.095 & 0.122 & 1.566 \\
\hline 14 & FIOCCHI PALACE & 3850 & 0.600 & 0.000 & 0.199 & 0.288 & 0.130 & 0.026 & 1.243 \\
\hline 15 & ST. SPIRIT'S CHURCH & 2180 & 0.800 & -0.153 & 0.160 & 0.000 & 0.178 & 0.413 & 1.399 \\
\hline 16 & DE FALCO PALACE & 1800 & 1.000 & 0.056 & 0.465 & 0.719 & 0.216 & 0.278 & 2.734 \\
\hline 17 & "MADONNA OF HAY” CHURCH & 2000 & 1.000 & -1.250 & 0.349 & 0.833 & 0.250 & 0.450 & 1.631 \\
\hline 18 & CONVEN TO GAIANO & 1950 & 0.400 & 0.000 & 0.322 & 0.000 & 0.256 & 0.051 & 1.030 \\
\hline 19 & ST. SOSSIO'S CHURCH & 900 & 0.800 & 0.056 & 0.554 & 0.617 & 0.309 & 0.556 & 2.891 \\
\hline 20 & SEVENTEENTH-CENTURY BUILDING & 1170 & 0.400 & -0.142 & 0.369 & 0.000 & 0.237 & 0.427 & 1.291 \\
\hline
\end{tabular}

In bold: values relating to the selected projects.

The problem is faced by considering the projects to be selected how binary variables $\{0,1\}$, according to whether the $i$ th project is included (value 1 ) or not (value 0 ) in the investment programme.

In mathematical terms, the reference model assumes the form:

$$
\left\{\begin{array}{l}
\max \sum_{i}\left(\text { QUALITY }_{i}+\text { ACTION }_{i}+\mathrm{IRR}_{i}+\text { No. } \text { WORKERS }_{i}+\mathrm{COM}_{i}-\mathrm{IMPA}_{i}\right) * x_{i} \\
\sum_{\substack{i \\
x_{i} \in\{0,1\}(i=1, \ldots, n)}} C_{i} * x_{i} \leq \text { BUDGET }
\end{array}\right.
$$

In the AMPL programming environment, to the .mod file (see Table 1 ) is associated with the dat file (Table 4) that reports the synthesis data of the Multicriteria analysis conducted for each of the twenty conservation and valorization projects.

At this point, .mod and dat files are called in the AMPL command line, specifying the solver implementing the Branch \& Bound algorithm.
The optimal combination that is obtained is made up of the projects:

$3-4-5-10-11-12-16-19-20$.

The maximum value of the objective function is 23,64 , for a total investment cost of 9900 thousand euro. Thus, the available budget of 10,000 thousand is almost completely employed, and only residual 100 thousand euros.

The list of best project combinations can be obtained by using $\varepsilon$-costrained algorithm of the type:

objective $i \leq$ objective $(i-1)-\varepsilon$

In doing so, we have the first ten combinations in Table 5, wherein for each of them is provided the value of the objective function and the investment cost. Obviously, the first combination is the optimal one already mentioned. 
Table 4

dat file.

\begin{tabular}{|c|c|c|c|c|c|c|c|}
\hline param & $\begin{array}{l}\text { C1 } \\
\text { QUAL }\end{array}$ & $\begin{array}{l}\text { C2 } \\
\text { ACTION }\end{array}$ & $\begin{array}{l}\text { C3 } \\
\text { IRR }\end{array}$ & $\begin{array}{l}\text { C4 } \\
\text { No. of workers }\end{array}$ & $\begin{array}{l}\text { C5 } \\
\text { COM }\end{array}$ & $\begin{array}{l}\text { C6 } \\
\text { IMPA }\end{array}$ & param COSTS:= \\
\hline 1 & 0.400 & 0.000 & 0.209 & 0.000 & 0.259 & 0.200 & 1500 \\
\hline 2 & 0.600 & 0.000 & 0.211 & 0.317 & 0.159 & 0.057 & 2000 \\
\hline 3 & 1.000 & 1.000 & 0.854 & 0.000 & 1.000 & 1.000 & 500 \\
\hline 4 & 0.600 & 0.159 & 0.306 & 0.705 & 0.026 & 0.333 & 2000 \\
\hline 5 & 0.400 & 0.000 & 0.495 & 0.925 & 0.167 & 0.300 & 1100 \\
\hline 6 & 0.800 & 0.000 & 0.228 & 0.537 & 0.161 & 0.032 & 3000 \\
\hline 7 & 1.000 & -0.069 & 0.285 & 0.540 & 0.023 & 0.208 & 2400 \\
\hline 8 & 0.400 & 0.030 & 0.387 & 0.000 & 0.051 & 0.273 & 2100 \\
\hline 9 & 0.400 & 0.000 & 0.204 & 0.658 & 0.178 & 0.107 & 2810 \\
\hline 10 & 0.800 & 0.135 & 0.476 & 1.000 & 0.338 & 0.473 & 1480 \\
\hline 11 & 0.600 & 0.000 & 1.000 & 0.000 & 0.185 & 0.333 & 2300 \\
\hline 12 & 0.400 & 0.256 & 0.649 & 0.569 & 0.085 & 0.154 & 650 \\
\hline 13 & 0.800 & 0.049 & 0.139 & 0.361 & 0.095 & 0.122 & 2100 \\
\hline 14 & 0.600 & 0.000 & 0.199 & 0.288 & 0.130 & 0.026 & 2800 \\
\hline 15 & 0.800 & -0.153 & 0.160 & 0.000 & 0.178 & 0.413 & 2180 \\
\hline 16 & 1.000 & 0.056 & 0.465 & 0.719 & 0.216 & 0.278 & 1800 \\
\hline 17 & 1.000 & -1.250 & 0.349 & 0.833 & 0.250 & 0.450 & 2000 \\
\hline 18 & 0.400 & 0.000 & 0.322 & 0.000 & 0.256 & 0.051 & 1950 \\
\hline 19 & 0.800 & 0.056 & 0.554 & 0.617 & 0.309 & 0.556 & 900 \\
\hline 20 & 0.400 & -0.142 & 0.369 & 0.000 & 0.237 & 0.427 & 2170 \\
\hline
\end{tabular}

param $\mathrm{p} 1:=1$

param $\mathrm{p} 2:=1$

param $\mathrm{p} 3:=1$.

param $\mathrm{p} 4:=1$.

param $\mathrm{p} 5:=1$

param $\mathrm{p} 6:=1$

Table 5

List of best project combinations.

\begin{tabular}{|c|c|c|c|}
\hline \multicolumn{2}{|c|}{ Combination projects } & \multirow{2}{*}{$\begin{array}{l}\text { Objective function } \\
23,640\end{array}$} & \multirow{2}{*}{$\begin{array}{l}\text { Costs (in thousand of } € \text { ) } \\
9.900\end{array}$} \\
\hline 1 & $3-4-5-10-11-12-16-19-20$ & & \\
\hline 2 & $3-4-5-8-10-11-12-16-19$ & 23,490 & 9.840 \\
\hline 3 & $3-5-10-11-12-16-17-19-20$ & 23,143 & 9.800 \\
\hline 4 & $3-5-8-10-11-12-16-17-19$ & 22,993 & 9.740 \\
\hline 5 & $3-5-10-11-12-15-16-19-20$ & 22,909 & 9.980 \\
\hline 6 & $2-3-5-10-11-12-16-19-20$ & 22,855 & 9.550 \\
\hline 7 & $3-5-8-10-11-12-15-16-19$ & 22,759 & 9.920 \\
\hline 8 & $2-3-5-8-10-11-12-16-19$ & 22,705 & 9.490 \\
\hline 9 & $3-5-8-10-11-12-16-19-20$ & 22,656 & 8.910 \\
\hline 10 & $1-2-3-5-10-11-12-16-19$ & 22,632 & 9.880 \\
\hline
\end{tabular}

\section{Conclusions}

The intervention politics on the historical buildings not always achieves both objectives of the conservation and valorization. The frequent lack of a systemic vision of cultural heritage leads to neglecting the processes of valorization, which consist of "in the exercise of functions and in the discipline of activities aimed at promoting the knowledge of cultural heritage and ensuring the best conditions of use and public enjoyment of the heritage itself ..." (Article 29 of Legislative Decree No. 42 of 2004, "Code of cultural heritage and landscape") [61]. From this it is necessary to use analytical methodologies that are suitable for evaluating projects for the valorization of buildings of historical and artistic interest. In light of the plurality of effects-financial, social, cultural and environmental nature-which are intended to generate in the reference area, both during the realization of the works and during the period of operation, so with a typical approach of multi-criteria decision analysis.

Using linear programming algorithms, in the present work a model is outlined and tested for the investments selection able to receive the running instances of the community, with regard to the demands of enjoyment of the historical buildings and in report to the logic of sustainable territory development. The proposed economic model, structured around an objective function, in turn conditioned by coherent constraints, is able to take into account all the terms of the problem outlined. Moreover, it is possible through simple polynomial algebraic mathematical expressions easy to read and adaptability to different concrete situations, also with regard to the choice of indicators. For example, the introduction of appropriate coefficients in the maximization function allows the decision maker to assign a different weight to the evaluation criteria, thus taking into account specific policy needs. The result is the combination of projects that maximizes the objective function within the limits of the budget and other constraints which in turn can be established.

It should be noted that as the value of significant parameters changes, the model can simply provide the new results. It follows that the calculation algorithm allows to perform the sensitivity analysis.

The case study, which relates to the projects selection for the recovery of historical buildings located in the area next to the Campus of the Salerno University (Italy), testifies the methodological goodness of evaluation model and repeatability of the steps necessary to its implementation. The results, made through the 
identification of the initiatives to be financed, are of extreme importance in the light of the more general objectives of economic policy aimed at the optimum allocation of resources.

\section{References}

[1] The Getty Research Institute, Art \& Architecture Thesaurus Online, 2017.

[2] P. Scarzella, M. Zerbinatti, Recupero e conservazione dell'edilizia storica, Alinea Editrice, Firenze, 2009.

[3] C. Brandi, Teoria del restauro, Einaudi, Torino, 1977.

[4] E. Waterton, L. Smith, The utility of discourse analysis to heritage studies: the Burra Charter and social inclusion, Int. J. Herit. Stud. 12 (4) (2006) 339-355.

[5] S. Navrud, R.C. Ready, Valuing Cultural Heritage: Applying Environmental Valuation Techniques to Historic Buildings, Monuments and Artifacts, Edward Elgar Publishing Ltd, United Kingdom, 2002.

[6] M. Vecco, A definition of cultural heritage: from the tangible to the intangible, J. Cult. Herit. 11 (3) (2010) 321-324.

[7] A. Nesticò, M. Macchiaroli, O. Pipolo, Costs and benefits in the recovery of historic buildings: the application of an economic model, Sustainability 7 (11) (2015) 14661-14676, http://dx.doi.org/10.3390/su71114661.

[8] V. Del Giudice, P. De Paola, F. Torrieri, An integrated choice model for the evaluation of urban sustainable renewal scenarios, Adv. Mater. Res. 1030-1032 (2014) 2399-2406.

[9] C. Pahl-Wost, The implication of complexity for integrated resources management, Environ. Model. Softw. 22 (5) (2006) 561-569.

[10] F. Tajani, P. Morano, Concession and lease or sale? A model for the enhancement of public properties in disuse or underutilized, WSEAS Trans. Bus. Econ. 11 (2014) 787-800.

[11] C. Tweed, Built cultural heritage and sustainable development, Landsc. Urban Plan. 83 (1) (2007) 138-149.

[12] S. Pagiola, Economic Analysis of Investments in Cultural Heritage: Insights from Environmental Economics, World Bank, Washington, DC, 1996.

[13] A. Nesticò, M. Macchiaroli, O. Pipolo, Historic buildings and energetic requalification: a model for the selection of technologically advanced interventions, in: O. Gervasi, B. Murgante, S. Misra, M.L. Gavrilova, A.M.A.C. Rocha, C. Torre, D. Taniar, B.O. Apduhan (Eds.), ICCSA 2015, Part III, Vol. 9157 LNCS, 2015, pp. 61-76, http://dx.doi.org/10.1007/978-3-319-21470-2_5.

[14] M.R. Guarini, A. Chiovitti, F. Battisti, P. Morano, An integrated approach for the assessment of urban transformation proposals in historic and consolidated tissues, in: G. Borruso, et al. (Eds.), ICCSA 2017, Vol. 10406 LNCS, 2017, pp. 562-574.

[15] A.J. Hillman, G.D. Keim, Shareholder value, stakeholder management, and social issues: what's the bottom line? Strateg. Manag. J. 22 (2) (2001) 125-139.

[16] S.D. Brody, Measuring the effects of stakeholder participation on the quality of local plans based on the principles of collaborative ecosystem management, J. Plan. Educ. Res. 22 (4) (2013) 407-419.

[17] A. Voinov, F. Bousquet, Modelling whit stakeholders, Environ. Model. Softw. 25 (11) (2010) 1268-1281.

[18] A. Nesticò, G. De Mare, Government tools for urban regeneration: the cities plan in Italy. A critical analysis of the results and the proposed alternative, in: B. Murgante, S. Misra, A.M.A.C. Rocha, C. Torre, J.G. Rocha, M.I. Falcão, D. Taniar, B.O. Apduhan, O. Gervasi (Eds.), ICCSA 2014, Part II, Vol. 8580 LNCS, 2014, pp. 547-562, http://dx.doi.org/10.1007/978-3-319-09129-7_40.

[19] S. Barile, et al., An introduction to the viable systems approach and its contribution to marketing, J. Bus. Mark. Manag. 5 (2) (2012) 54-78.

[20] T.H. Tuan, S. Navred, Capturing the benefits of preserving cultural heritage, J. Cult. Herit. 9 (3) (2008) 326-337.

[21] O. Keitumetse Susan, Cultural resources as sustainability enablers: towards a community-based cultural heritage resources management (COBACHREM) model, Sustainability 6 (1) (2014) 70-85

[22] A. Bedate, L.C. Herrero, J.À. Sanz, Economic valuation of the cultural heritage: application to four case studies in Spain, J. Cult. Herit. 5 (1) (2004) 101-111.

[23] V. Ferretti, M. Bottero, G. Mondini, Decision making and cultural heritage: an application of the multi-attribute value theory for the reuse of historical buildings, J. Cult. Herit. 15 (6) (2014) 644-655.

[24] I. Rizzo, D. Throsby, Cultural heritage: economic analysis and public policy, Handb. Econ. Art Cult. 1 (2006) 983-1016

[25] A. Bàez, L.C. Herrero, Using contingent valuation and cost-benefit analysis to design a policy for restoring cultural heritage, J. Cult. Herit. 13 (2) (2012) 235-245.

[26] S. Choi Andy, B.W. Ritchie, F. Papandrea, J. Bennett, Economic valuation of cultural heritage sites: a choice modelling approach, Tour. Manag. 31 (2) (2010) 213-220.
[27] M. Mazzanti, Cultural heritage as multi-dimensional, multi-value and multiattribute economic good: toward a new framework for economic analysis and valuation, J. Socio-Econ. 31 (5) (2002) 529-558.

[28] L. Fusco Girard, La valutazione delle risorse architettonico-culturali, Aestimum 13 (2009) 153-164.

[29] P. Nijkamp, A multidimensional evaluation of monuments, Res. Memo. 71 (1987) 1-19.

[30] G. Munda, Social Multi-Criteria Evaluation for a Sustainable Economy, vol. 17, 2008.

[31] C. Vercellis, Ottimizzazione, Teoria, metodi e applicazioni, The McGraw-Hill Companies, Milano, 2008

[32] R.L. Rardin, L.R. Ronald, Optimization in Operations Research, vol. 166, 1998.

[33] B. Korte, J. Fonlupt, J. Vygen, Optimisation Combinatoire: Theorie et Algorithms, Springer, Verlay-France, 2010.

[34] K.J. Sengupta, A.F. Karl, Economic Analysis and Operations Research: Optimization Techniques in Quantitative Economic Models, North-Holland Publishing Company, Amsterdam, 1969.

[35] C. Koboldt, Optimizing the use of cultural heritage, in: M. Hutter, I. Rizzo (Eds.), Economic Perspectives on Cultural Heritage, MacMillan Press, London, UK, 1997, pp. 50-73 (Chapter 4).

[36] W. Bo, X. Xia, J. Zhang, A multi-objective optimization model for the life-cycle cost analysis and retrofitting planning of buildings, Energy Build. 77 (2014) 227-235.

[37] H.M. Markowitz, Portfolio selection, J. Financ. 7 (1) (1952) 77-91.

[38] F.S. Roberts, Discrete Mathematical Models with Applications to Social, Biological and Environmental Problems, Prentice-Hall, 1976.

[39] M. Dallocchio, Finanza d'azienda. Analisi e valutazioni per le decisioni d'impresa, EGEA, Milano, 1995.

[40] E.J. Farragher, R.T. Kleiman, A re-examination of real estate investment decision making practice, J. Real Estate Portf. Manag. 2 (1) (1996) 31-39.

[41] T. Cooke-Davies, The "real" success factors on projects, Int. J. Proj. Manag. 20 (3) (2002) 185-190.

[42] D.L. Olson, Multiple criteria optimization: theory, computation, and application, in: Wiley Series in Probability and Mathematical Statistics Applied, 1996.

[43] E. Elton, M. Gruber, S. Brown, W. Goetzmann, Modern Portfolio Theory and Investment Analysis, 6th ed., John Wiley and Sons, 2003.

[44] M.G. Kaiser, F.E. Arbi, F. Ahlemann, Successful project portfolio management beyond project selection techniques: understanding the role of structural alignment, Int. J. Proj. Manag. 33 (1) (2015) 126-139.

[45] E. Chiveco, Integration of linear programming and GIS for land-use modelling, Int. J. Geogr. Inf. Sci. 7 (1) (1993) 71-83.

[46] C.J.H. Aerts Jeroen, E. Eisinger, B.M. Gerard Heuvelink, J.T. Stewart, Using linear integer programming for multi-site land-use allocation, Geogr. Anal. 35 (2) (2003) 148-169.

[47] R.L. Church, Geographical information systems and location science, Comput. Oper. Res. 29 (6) (2002) 541-562.

[48] T. Shirabe, A model of contiguity for spatial unit allocation, Geogr. Anal. 37 (1) (2005) 2-16.

[49] A. Ligmann-Zielinska, L. Church Richard, P. Jankowski, Spatial optimization as a generative technique for sustainable multiobjective land-use allocation, Int J. Geogr. Inf. Sci. 22 (6) (2008) 601-622.

[50] J. Stewart Theodor, R. Janssen, M. Van Herwijnen, A genetic algorithm approach to multiobjective land use planning, Comput. Oper. Res. 31 (14) (2004) 2293-2313.

[51] L.C. Dias, V. Mousseau, IRIS: a DSS for multiple criteria sorting problems, J. Multi-Criteria Decis. Anal. 12 (4/5) (2005) 1-14

[52] E. Esposito, P. Rostirolla, Problema decisionale e tecniche di aiuto alla decisione, in: AA.VV., "I beni culturali. Linee guida di programmazione e di valutazione dei progetti", StrumentiFormez n.6, Formez, Roma, 1993.

[53] P. Rosato, Un modello di analisi multicriteri per la localizzazione di infrastrutture lineari in aree ad insediamento diffuso, Aestimum 36 (1998).

[54] F. Tajani, P. Morano, An evaluation model of the financial feasibility of social housing in urban redevelopment, Prop. Manag. (2) (2015) 133-151.

[55] G. Dantzig, Linear Programming and Extensions, Princeton University Press, 2016.

[56] A. Nesticò, F. Sica, The sustainability of urban renewal projects: a model for economic multi-criteria analysis, J. Prop. Invest. Financ. 35 (4) (2017) 397-409, http://dx.doi.org/10.1108/JPIF-01-2017-0003.

[57] R.G. Parker, R.L. Rardin, Discrete Optimization, Academy Press, 1988

[58] G.J. Thusen, W.J. Fabrycky, Economia per ingegneri, Il Mulino-Prentice Hall, Bologna, Italia, 1994

[59] L.A. Wolsey, Integer Programming, Wiley and Sons, 1998.

[60] A. Sforza, Modelli e metodi della Ricerca Operativa, Edizioni Scientifiche Italiane, Napoli, Italia, 2002

[61] Codice dei beni culturali e del paesaggio, D.to leg.vo 42, Roma, Italia, 2004 